\title{
Sequencing of Cabazitaxel in Metastatic Castrate-Resistant Prostate Cancer: A Case Report
}

\author{
Donald Colbourn \\ Sutter Roseville Medical Center, Roseville, Calif., USA
}

\section{Key Words}

Cabazitaxel · Castrate-resistant prostate cancer (CRPC) - Treatment sequencing

\begin{abstract}
Prostate cancer is a common cancer in men; for metastatic disease, it has a 5 -year survival rate of $30 \%$. No FDA-approved therapy for castrate-resistant prostate cancer (CRPC) known to improve survival was available until 2004, when based on a significant survival benefit over mitoxantrone, docetaxel in combination with prednisone was approved. In combination with prednisone, cabazitaxel, which was approved in the United States in 2010, is indicated for patients with metastatic CRPC previously treated with a docetaxel-containing regimen. This case report describes the treatment of a man 58 years of age who was diagnosed with advanced prostate cancer in 2006 . He was initially managed with radical prostatectomy followed by androgen deprivation therapy, but a rising prostate-specific antigen (PSA) level led to enrollment in a clinical trial of HE3235 for 6 months. Subsequently, with progression of disease, he was treated with docetaxel for 4 months and then palliative radiation therapy. Cabazitaxel was initiated in October 2010; his condition stabilized within weeks, and he experienced a progressive decline in his PSA level from a peak of $5,424 \mathrm{ng} / \mathrm{ml}$. Continued treatment with cabazitaxel resulted in his being weaned off pain medications and resuming his normal activities. After 16 cycles of cabazitaxel, his PSA declined to $994 \mathrm{ng} / \mathrm{ml}$ as of January 2012. He tolerated the cabazitaxel well and occasionally received myeloid growth factors for treatment of neutropenia; otherwise, he experienced only mild diarrhea. This response to cabazitaxel is notable, particularly in light of prior failure of multiple therapies.
\end{abstract}

\section{Introduction}

Prostate cancer is the most common non-skin cancer in men, with an estimated 240,890 new cases and 33,720 deaths in 2011 [1]. The 5 -year survival rate is approximately $100 \%$ for locoregional disease, but only $30 \%$ for metastatic disease [1]. In metastatic prostate cancer, androgen deprivation therapy (ADT) with medical or 
surgical castration typically achieves only temporary disease control, as virtually all men progress to develop castrate-resistant prostate cancer (CRPC) [2]. Until 2004, when docetaxel-based chemotherapy was shown to provide a significant 2-month survival advantage compared with the combination of mitoxantrone plus prednisone, no FDA-approved therapy for CRPC known to improve survival was available $[3,4]$.

The year 2010 marked a further advance in the treatment of CRPC with publication of the results of an open-label, randomized, phase III clinical trial of cabazitaxel (TROPIC) and the first US Food and Drug Administration (FDA) approval of a treatment for patients whose disease progressed following docetaxel treatment. Cabazitaxel, a novel taxane with a microtubule-stabilizing potency similar to other taxanes, demonstrated activity against tumor cell lines resistant to the taxanes paclitaxel and docetaxel [5-7]. The TROPIC trial studied men with metastatic CRPC (mCRPC; $\mathrm{n}=755$ ) previously treated with docetaxel [8]. Enrolled patients received prednisone $10 \mathrm{mg}$ daily and either cabazitaxel $25 \mathrm{mg} / \mathrm{m}^{2}$ or mitoxantrone $12 \mathrm{mg} / \mathrm{m}^{2}$ every 3 weeks [8]. The median overall survival was 15.1 months in the cabazitaxel group compared with 12.7 months in the mitoxantrone group, corresponding to a $30 \%$ reduction in relative risk of death (hazard ratio $0.70 ; 95 \%$ confidence interval 0.59-0.83; $p<0.0001$ ) [8]. Grade $\geq 3$ adverse events (AEs) in the cabazitaxel group included neutropenia (82\%), leukopenia (68\%), anemia (11\%), febrile neutropenia (8\%), diarrhea (6\%), fatigue (5\%), asthenia (5\%), and thrombocytopenia (4\%) [8].

Cabazitaxel is one of several promising therapies for mCRPC in development or approved by the FDA. One agent currently in development is HE3235 (Apoptone ${ }^{\mathrm{TM}}$ ), an oral analog of the testosterone metabolite $3-\beta$-androstanediol that is formed in prostate tissue [9]. Preclinical studies of HE3235 in rodent models of prostate $[10,11]$ and breast [12] cancer demonstrate good activity in controlling the incidence, growth, and development of new tumors. Preliminary results of a phase I/IIa clinical trial of patients with taxane-resistant mCRPC $(\mathrm{n}=68)$ showed that HE3235 is safe and well tolerated. Reductions in circulating tumor cells were observed in all patients, as well as favorable responses in bone scans in some patients ranging from decrease of tracer uptake to resolution of some bone tumors [13]. This report describes my experience in treating a patient with mCRPC with multimodal therapy, including HE3235 and cabazitaxel.

\section{Case Report}

An active, 58-year-old man was diagnosed with T3b, Gleason grade 9 prostate cancer in September 2006. He underwent a radical prostatectomy followed by radiation therapy for positive margins. He subsequently received ADT until January 2009, at which time treatment with bicalutamide, goserelin, and prednisone was initiated. Although the patient remained asymptomatic, his prostate-specific antigen (PSA) level was found to be $4.9 \mathrm{ng} / \mathrm{ml}$ in December 2008. A bone scan revealed a single spot at the L1 vertebrae, and a ProstaScint scan showed positive residual prostate cancer with mesenteric involvement. His PSA was $5.6 \mathrm{ng} / \mathrm{ml}$ in February 2009, at which time, zoledronic acid was initiated. PSA peaked at $7.4 \mathrm{ng} / \mathrm{ml}$ in March 2009, and then ranged from 4.97 to $5.5 \mathrm{ng} / \mathrm{ml}$ through August 2009. The patient remained asymptomatic.

In October 2009, the patient's PSA was $12.5 \mathrm{ng} / \mathrm{ml}$, but increased to $22.4 \mathrm{ng} / \mathrm{ml}$ in November 2009 . This prompted discontinuation of bicalutamide, goserelin, and prednisone, and enrollment of the patient in a clinical trial HE3235-0201 (HE3235 $100 \mathrm{mg}$ orally once daily; ClinicalTrials.gov ID No. NCT00716794) in January 2010. The patient developed mild achiness from discontinuation of the prednisone, but otherwise remained asymptomatic. During treatment with HE3235, some bone scans showed improvement, while others did not. Computed tomography scans of the abdomen and pelvis 
demonstrated stable disease. However, the patient's PSA continued to rise, reaching 3,484 ng/ml in June 2010. He developed shortness of breath, and laboratory results revealed anemia, thrombocytopenia, low fibrinogen level, elevated fibrinogen degradation products, and lactate dehydrogenase levels consistent with disseminated intravascular coagulation (DIC). He was taken off the study and HE3235 was discontinued in June 2010; docetaxel $75 \mathrm{mg} / \mathrm{m}^{2}$ every 3 weeks was initiated.

The patient's PSA dropped to $1,922 \mathrm{ng} / \mathrm{ml}$ in July 2010, subsequent to the first dose of docetaxel; $1,457 \mathrm{ng} / \mathrm{ml}$ after the second dose; and then $1,096 \mathrm{ng} / \mathrm{ml}$ on August 10, 2010, at which time the DIC resolved. However, PSA rose to 2,448 ng/ml on September 1, 2010. The final dose of docetaxel was administered on September 10, 2010. Occasional nighttime pain increased to severe back pain accompanied by nausea and vomiting, leading to hospital admission on October 7, 2010, at which time samarium SM 153 lexidronam was initiated. On hospital admission, PSA was 4,728 ng/ml and there was laboratory evidence of DIC. From October 11-22, 2010, the patient received 30 Gy of radiation therapy in 10 fractions from L1 to bilateral SI joints. His pain was managed with transdermal fentanyl $50 \mu \mathrm{g} / \mathrm{h}$ and, during this time, his performance status (PS) was 3.

Cabazitaxel $25 \mathrm{mg} / \mathrm{m}^{2}$ every 3 weeks was initiated October 30,2010, at which time the patient's PSA was $5,424 \mathrm{ng} / \mathrm{ml}$. PSA declined to $4,584 \mathrm{ng} / \mathrm{ml}$ on November 19,2010 , and 3,952 $\mathrm{ng} / \mathrm{ml}$ in December 2010. Shortly after cabazitaxel was initiated, the patient's hematologic profile worsened (white blood cell [WBC] count 1,900/ $\mu \mathrm{l}$, hemoglobin $8.7 \mathrm{~g} / \mathrm{dl}$, platelets $61,000 / \mu \mathrm{l}$ ) although his condition was stable and his PS improved to 2 . The patient's WBC count returned to normal following short-term administration of filgrastim. His fibrinogen level returned to normal by mid-November and his platelet count steadily improved over 2 months.

On March 30, 2011, the patient was admitted with a bleeding gastrointestinal ulcer, which was successfully treated. Cabazitaxel was continued as scheduled. Back pain was adequately managed with low-dose transdermal fentanyl; the patient's PS was 1. By August 2011, the patient had completed 10 cycles of cabazitaxel. He received occasional doses of epoetin alfa for anemia and filgrastim for neutropenia. A finding of hypocalcemia led to discontinuation of zoledronic acid. PSA levels were 1,246 ng/ml (early August 2011), 1,376 ng/ml (late August 2011), and 1,221 ng/ml (September 2011). In mid-September 2011, the patient began to experience mild numbness in his toes and mild nausea, but remained active with a PS of 1 . The patient was weaned off pain medications, and has not required treatment for breakthrough pain. He has had mild episodes of diarrhea, but has not required additional hydration. As of the patient's last office visit on January 9 , 2012, he continues to experience mild side effects of therapy, but has returned to all of his normal activities. His PSA has declined to $994 \mathrm{ng} / \mathrm{ml}$.

\section{Discussion}

This case highlights many of the challenges encountered in managing patients with mCRPC. Prostate cancer progresses through several stages of diseases, with different treatment options appropriate for each stage, and a rapidly expanding list of therapies indicated for MCRPC. In this case, early management with surgery and radiation followed by ADT provided initial benefit, but as in many cases, the patient progressed to CRPC. The combination of bicalutamide, a luteinizing hormone-releasing hormone agonist, and prednisone provided little benefit. Thus, having failed multiple modes of treatment, the patient was enrolled in a clinical trial, which is one of several recommended options in the 2010 National Comprehensive Cancer Network guidelines [14].

The patient was enrolled in a trial of the investigational agent HE3235, which had demonstrated anticancer effects in preclinical prostate cancer models $[10,11]$. He experienced some improvement on bone scans and disease stabilization on CT scans. His PSA level rose, but this was not initially considered a sign of disease progression as 
it had been seen in other patients responding to HE3235, and was noted to be common in preclinical animal models responding favorably $[10,11]$. However, progressive increase in PSA level and development of DIC prompted discontinuation of HE3235 after 6 months. Development of DIC is a known complication of advanced CRPC, and carries a very poor prognosis. Subsequent treatment with docetaxel decreased the patient's PSA level and improved his DIC, but symptoms worsened after a short interval.

Treatment with cabazitaxel was initiated shortly after FDA approval in 2010. The patient achieved a good response as evidenced by the progressive decline in the PSA level, resolution of DIC, and adequate pain relief achieved with single-agent opioid analgesia. In addition, the patient's PS improved such that he was able to resume his favorite activities, particularly fishing. The results observed with cabazitaxel therapy are consistent with those observed in TROPIC, including hematologic AEs consisting of leukopenia, anemia, and thrombocytopenia, experienced by the patient shortly after initiation of cabazitaxel. Use of filgrastim and epoetin alfa to address hematologic toxicities enabled the patient to complete 16 cycles of cabazitaxel through January 2012 with limited additional AEs.

The response of this patient to cabazitaxel is notable, particularly given his failure with multiple therapies, and indicates that cabazitaxel represents an important advance in the management of patients with CRPC who have failed docetaxel therapy. The use of HE3235 prior to docetaxel and 9 months prior to cabazitaxel may have positively benefitted the patient through an as-yet-unknown mechanism. Preclinical investigation in a rat model of breast cancer has shown that the anti-cancer activity of HE3235 was enhanced when combined with docetaxel without evidence of increased toxicity [12].

These observations point to the need for further investigation of cabazitaxel to determine its optimal role in managing patients with CRPC, either as sequential therapy, in combination with other therapies, or as first-line therapy in place of docetaxel [15].

\section{Conclusion}

This case report illustrates the encouraging improvement in survival for metastatic CRPC possible due to the increase in treatment options.

\section{Acknowledgements}

Medical editorial assistance was provided by Eric Block, PhD of Phase Five Communications Inc., funded by sanofi-aventis U.S., a SANOFI company.

\section{Disclosure Statement}

The author retained full editorial control over the content of this manuscript, and received no compensation from any party for this work. He has no potential conflicts of interest to declare. 


\section{References}

1 Siegel R, Ward E, Brawley 0, Jemal A: Cancer statistics, 2011: the impact of eliminating socioeconomic and racial disparities on premature cancer deaths. CA Cancer J Clin 2011;61:212-236.

-2 Di Lorenzo G, Buonerba C, Autorino R, De PS, Sternberg CN: Castration-resistant prostate cancer: current and emerging treatment strategies. Drugs 2010;70:983-1000.

3 Petrylak DP, Tangen CM, Hussain MH, Lara PN Jr, Jones JA, Taplin ME, Burch PA, Berry D, Moinpour C, Kohli M, Benson MC, Small EJ, Raghavan D, Crawford ED: Docetaxel and estramustine compared with mitoxantrone and prednisone for advanced refractory prostate cancer. N Engl J Med 2004;351:15131520.

-4 Tannock IF, de Wit R, Berry WR, Horti J, Pluzanska A, Chi KN, Oudard S, Théodore C, James ND, Turesson I, Rosenthal MA, Eisenberger MA; TAX 327 Investigators: Docetaxel plus prednisone or mitoxantrone plus prednisone for advanced prostate cancer. N Engl J Med 2004;351:1502-1512.

5 Bissery MC: Preclinical evaluation of new taxoids. Curr Pharm Des 2001;7:1251-1257.

6 Bissery MC, Bouchard H, Riou JF, Vrignaud P, Combeau C, Bourzat JD, Commercon A, Lavelle F: Preclinical evaluation of TXD258, a new taxoid. In: Proceedings from the American Association of Cancer Research; April 1-5, 2000; San Francisco, CA. Abstract 1364.

-7 Mita AC, Denis LJ, Rowinsky EK, Debono JS, Goetz AD, Ochoa L, Forouzesh B, Beeram M, Patnaik A Molpus K, Semiond D, Besenval M, Tolcher AW: Phase I and pharmacokinetic study of XRP6258 (RPR 116258A), a novel taxane, administered as a 1-hour infusion every 3 weeks in patients with advanced solid tumors. Clin Cancer Res 2009;15:723-730.

-8 de Bono JS, Oudard S, Ozguroglu M, Hansen S, Machiels JP, Kocak I, Gravis G, Bodrogi I, Mackenzie MJ Shen L, Roessner M, Gupta S, Sartor AO; TROPIC Investigators: Prednisone plus cabazitaxel or mitoxantrone for metastatic castration-resistant prostate cancer progressing after docetaxel treatment: a randomised open-label trial. Lancet 2010;376:1147-1154.

-9 Ahlem C, Kennedy M, Page T, Bell D, Delorme E, Villegas S, Reading C, White S, Stickney D, Frincke J: 17alpha-Alkynyl 3alpha, 17beta-androstanediol non-clinical and clinical pharmacology, pharmacokinetics and metabolism. Invest New Drugs 2012;30:59-78.

10 Trauger R, Corey E, Bell D, White S, Garsd A, Stickney D, Reading C, Frincke J: Inhibition of androstenediol-dependent LNCaP tumour growth by 17 alpha-ethynyl-5alpha-androstane-3alpha, 17beta-diol (HE3235). Br J Cancer 2009;100:1068-1072.

11 Koreckij TD, Trauger RJ, Montgomery RB, Pitts TE, Coleman I, Nguyen H, Reading CL, Nelson PS, Vessella RL, Corey E: HE3235 inhibits growth of castration-resistant prostate cancer. Neoplasia 2009;11:12161225.

12 Ahlem CN, Frincke JM, White SK, Reading CL, Trauger RJ, Lakshmanaswamy R: 17-alpha-ethynyl-5alpha-androstane-3-alpha, 17-beta-diol treatment of MNU-induced mammary cancer in rats. Int J Breast Cancer 2011;2011:618757.

13 Harbor BioSciences wraps up phase I/IIa prostate cancer study [press release]. San Diego, CA: Harbor BioSciences; November 30, 2011.

14 National Comprehensive Cancer Center (NCCN). NCCN Clinical Practice Guidelines in Oncology. Prostate cancer. V.1.2010. http://img.medscape.com/article/715/312/ProstateV.1_2010(Medscape).pdf. Accessed January 18, 2012.

15 Small EJ, de Bono JS: Prostate cancer: evolution or revolution? J Clin Oncol 2011;29:3595-3598. 